\title{
Giovanni Berlinguer - entre o cotidiano e as fronteiras da vida humana
}

\author{
Giovanni Berlinguer - between the quotidian and the borders of \\ human life
}

Volnei Garrafa', Paulo Duarte de Carvalho Amarante 2

RESUMO O texto apresenta brevemente a vida do cientista e político italiano Giovanni Berlinguer, falecido em abril de 2015 aos 90 anos de idade. Analisa sua biografia pessoal, além de comentar resumidamente sua exemplar trajetória científica e política. Apresenta também algumas das atividades por ele desenvolvidas em suas frequentes viagens pela América Latina. Além disso, discute o legado por ele deixado para as gerações futuras e sua importante contribuição para a politização da bioética internacional por meio da inclusão dos temas sanitários e sociais na sua agenda.

PALAVRAS-CHAVE Biografia; Democracia; Saúde pública; Bioética.

ABSTRACT The paper briefly presents the life of the Italian scientist and politician Giovanni Berlinguer, who died in April 2015 when he was 90 years old. It also analyzes its personal biography, and briefly reviews his rich scientific and political history. It also presents some of the activities undertaken by him in his frequent trips throughout Latin America. Furthermore, it discusses his legacy for future generations and his important contribution to the politicization of international bioethics through the inclusion of health and social issues on its agenda.

KEYWORDS Biography; Democracy; Public health; Bioethics.

1Universidade de Brasília

(UnB), Faculdade de

Ciências da Saúde/

Cátedra Unesco de

Bioética e Programa de

Pós-Graduação em Bioética

- Brasília (DF), Brasil.

garrafavolnei@gmail.com

2 Fundação Oswaldo Cruz (Fiocruz), Escola Nacional de Saúde Pública Sergio Arouca (Ensp) - Rio de Janeiro (RJ), Brasil.

pauloamarante@gmail.com 


\section{Introdução}

Giovanni Berlinguer, além de médico, cientista e político, foi uma personalidade de referência da cultura, da ciência e da política italiana e mundial no século XX. Ele nasceu em Sassari, na ilha de Sardenha no dia 9 de julho de 1924 e morreu em 7 de abril de 2015, em Roma, com 90 anos de idade. Pela sua importância histórica para a República Italiana, o seu corpo foi velado na Câmera Ardente, aberta ao público durante dois dias intensos no Campidoglio, o histórico palácio presidencial no país, seguido por emotivas cerimônias fúnebres emocionadas na Aula Magna da Universidade de Sapienza, à qual ele dedicou três décadas de proveitosa vida acadêmica.

Toda sua vida foi marcada por uma ação acadêmica e política profundamente coerente com os princípios que ele abraçou ao longo da sua existência. Desde muito cedo abraçou o marxismo, filiando-se ao Partido Comunista Italiano (PCI), ao qual se manteve fiel até o seu fechamento nos anos 1990. Na Universidade, se caracterizou por ser um pesquisador crítico, avançado para o seu tempo, tentando - através da prática dialética - especialmente compreender e propor soluções para as inaceitáveis disparidades sociais constatadas no mundo contemporâneo. Ateu por convicção, jamais deixou de tratar todas as religiões, seus representantes e seguidores, com respeito e dignidade, ao ponto de, em muitas circunstâncias, ter sido convidado a eventos organizados por grupos acadêmicos de diferentes origens e tendências religiosas. Como italiano, manteve uma relação distante, porém sempre respeitosa, com a Igreja Católica, mesmo quando, enquanto deputado, foi o relator da vitoriosa lei do aborto naquele país.

O objetivo do presente texto é fazer um breve percurso pela biografia acadêmica e política deste ilustre personagem, registrando algumas das suas principais características e o legado que ele deixou para a humanidade, muito especialmente nos campos da medicina social, da saúde pública e da bioética.

\section{Biografia científica}

Filho do notável advogado Mario Berlinguer, que foi defensor dos direitos humanos durante a resistência italiana na primeira metade do século passado, e especialmente durante as duas grandes guerras mundiais, começou a sua carreira acadêmica como professor de medicina social na universidade local, na ilha de Sarda, até 1974. A partir desse ano, assumiu a cátedra de Saúde do Trabalho na Universidade La Sapienza, em Roma, onde ficou até se aposentar obrigatoriamente aos 75 anos em 1999.

Na universidade romana, Berlinguer, conquistou o título de professor titular através da notável defesa da sua tese na área biológica básica, pois, na época, seu departamento original (Biologia animal e humana) considerava as pesquisas sanitárias ligadas ao campo social (que eram do seu interesse) como 'coisas pouco científicas'. Por este motivo absurdo, escolheu estudar, com um tom bastante crítico, o assunto das 'pulgas italianas', assunto absolutamente original para a época e que proporcionou aos leitores, duas décadas depois, um bem-humorado livro intitulado 'Minhas pulgas', que teve como subtítulo 'como por meio delas me envolvi com a ciência', e no qual se autodenominou 'o maior - e único - especialista italiano em pulgas' (BERLINGUER, 1991A). Seu desejo, na época, era estudar as epidemias como a cólera e outras doenças que afetavam grandes contingentes populacionais e que ocorriam em diferentes regiões italianas. Infelizmente, como já foi dito, a academia asséptica da época, desaprovava os assuntos sanitário-sociais e coletivos, considerando-os de natureza não científicos.

Após o exame de cátedra pelo qual se formou professor pleno da universidade, introduziu definitivamente a temática 
$1 \mathrm{Na}$ ocasião do lançamento, na primeira quinzena de novembro de 1978, foi realizada uma matéria com Berlinguer que foi publicada na revista 'Saúde em Debate' no 09, a mesma em que foi publicado o documento político 'A questão democrática na área da saúde', que lançou as bases e a proposta do SUS. A matéria, intitulada 'Saúde não se troca por dinheiro' reproduz trechos da conferência baseada no livro, que Berlinguer pronunciou no Teatro Ruth Escobar (Revista Saúde em Debate, n. 9, jan./fev./mar. 1980, p. 41-46). histórica e sociopolítica no contexto da causalidade das doenças em Itália, e no mundo inteiro, pois as suas agudas e precisas contribuições também produziram fortes impactos na interpretação internacional da questão.

Suas atividades acadêmicas e políticas - como apresentaremos adiante - resultaram em profundas e decisivas mudanças na estrutura da atenção sanitária italiana, incluindo as decisões sobre o fechamento dos manicômios (BERLINGUER, 1968), e a aprovação legislativa e plebiscitária nacional das leis do aborto em um país que é berço do catolicisMO (BERLINGUER, 1978A, 1978B, 1978C).

'Psiquiatria e poder' foi o seu primeiro livro publicado no Brasil, por uma editora do estado de Minas Gerais no ano de 1976, e teve grandes repercussões por ser a primeira obra a difundir o extraordinário processo da reforma psiquiátrica desenvolvido e liderado pelo seu amigo Franco Basaglia na Itália, ainda antes da aprovação do próprio projeto de Lei que depois se tornou conhecido como a 'Lei Basaglia' e que determinou a extinção dos hospitais psiquiátricos do país (BERLINGUER, 1976B).

Outra das suas características que resulta indispensável registrar neste texto memorístico é a exemplar disciplina em publicar suas pesquisas, trabalhos, além de suas experiências legislativas, em revistas científicas especializadas e livros. Entre algumas das principais publicações da sua vasta obra, podem-se mencionar muito especialmente: ' $\mathrm{L} a$ macchina Uomo' (BERLINGUER, 1960); 'La sanità pubblica nella programazione economica 1964-1978' (BERLINGUER, 1964); 'Sicurezza e insecurezza sociale (BERLINGUER, 1968); 'Le salute nelle fabbriche' (BERLINGUER, 1969); 'La strage degli innocenti' (BERLINGUER; TERRANOVA, 1972); 'Medicina $y$ política' (BERLINGUER, 1973); 'La riforma sanitaria' (BERLINGUER, SCARPA, 1974); 'Infortuni sul lavoro dei minori' (BERLINGUER, CECCHINI; TERRANOVA, 1977); 'La malatia' (BERLINGUER, 1984). Por sua vez, 'Medicina e política' (BERLINGUER, 1978D), foi o primeiro livro internacional editado pelo Centro Brasileiro de Estudos de Saúde
(Cebes), histórica entidade acadêmica - política - sanitária brasileira fundada em 1976, na sua primeira coleção chamada 'Saúde em Debate', texto que se tornou um clássico obrigatório para a formação política dos profissionais de saúde do país na época ${ }^{1}$.

No final dos anos 1980, Berlinguer se apaixonou pela bioética, um novo campo de estudo que estava começando a tornar-se conhecido. Nas suas próprias palavras, "ho deciso di cambiare di strada”. Porém, apesar de abraçar esta disciplina, jamais abandonou sua área original da saúde pública. Pelo contrário, tentou construir uma nova e original 'ponte' entre a bioética e a saúde coletiva por meio do que chamou de 'bioética cotidiana', ou seja, a ética da vida 'daquelas coisas que acontecem todos os dias e que já não deveriam estar acontecendo'(BERLINGUER, 1991B; BERLINGUER, 2000).

Já na bioética, passou a ser convidado a grandes eventos internacionais como o V Congresso Mundial promovido pela International Association of Bioethics (IAB), realizado no Imperial Collegue, em Londres, no ano 2000, e o VI Congresso Mundial, realizado em Brasília, no ano 2002, sob o tema 'Bioética, Poder e Injustiça', no qual ministrou a conferência inaugural. Logo depois, em 2003, foi nomeado membro do International Bioethics Committee (IBC) da Unesco, sendo, conjuntamente com o filósofo filipino Leonardo de Castro, o relator principal dos primeiros rascunhos ligados à futura Declaração Universal sobre Bioética e Direitos Humanos, homologada em Paris dois anos depois, em 2005. Especialista internacional no assunto, Berlinguer foi membro da Junta Editorial da revista símbolo do Cebes - 'Saúde em Debate'.

No mesmo período foi designado como presidente do Comitê Nacional de Bioética de Itália, em um raro momento de espaço moralmente plural e politicamente laico da entidade, da que posteriormente seria presidente de honra. Recebeu também os prêmios 
de Doutor Honoris Causa nas universidades de Montreal/Canadá, La Habana/Cuba e Brasília/Brasil, além de muitas homenagens e mesmo um prêmio da Fundação Oswaldo Cruz, Rio de Janeiro, Brasil.

\section{Biografia política}

Giovanni Berlinguer começou cedo na política, inspirado pelo seu pai e pela companhia do seu irmão Enrico, que alguns anos depois se tornaría Secretário Geral do Partido Comunista Italiano (PCI) e um dos mais proeminentes líderes comunistas mundiais, ao ser o co-criador do Eurocomunismo, doutrina que confrontou o centralismo socialista soviético. Enquanto estudante, foi secretário e presidente da União Internacional de Estudantes entre os anos 1949 e 1953. Depois, entrou na vida política propriamente dita tornando-se um dos líderes mais importantes do PCI, respeitado e admirado até mesmo por seus adversários, pela forma respeitosa e elegante - apesar de sempre agudo e objetivo - de fazer política.

Ele teve uma intensa atuação legislativa. Com 84 anos de idade, foi eleito, com expressiva densidade eleitoral, deputado do Parlamento Europeu de Strasburgo pelo Partido Socialista Europeu. Anteriormente, tinha sido deputado em três legislaturas (1972, 1976 e 1979) e senador em outras duas (1983 e 1987). Foi também Conselheiro do Município de Roma, função para a qual foi reeleito no ano de 1985, sempre pelo seu amado PCI.

Personalidade do primeiro plano da cultura e da ciência italiana e mundial, contribuiu, através de sua atividade política, cultural e acadêmica nos campos da medicina social e da bioética - com seus mais de 40 livros e centenas de trabalhos acadêmicos publicados - à difusão da cultura científica e à análise crítica do sistema sanitário italiano e mundial. No seu país de nascimento, além do que já foi mencionado, foi também escolhido no ano 1999 como Cavaliere di Gran Croce dell'Ordine al merito della Repubblica Italiana e recebeu a Medalha de Ouro, no ano de 2001, concedida especialmente aos membros beneméritos da Cultura e da Arte da Itália.

Por causa das suas pesquisas e livros na área da saúde dos trabalhadores (BERLINGUER, 1968; BERLINGUER, 1977; BERLINGUER; CECCHIN; TERRANOVA, 1977; BERLINGUER, 1983), teve uma relação muito próxima com as centrais sindicais italianas, especialmente a CGIL (Centrale Generale Italiana dei Lavoratori) entidade historicamente próxima ao PCI. $\mathrm{Na}$ posse do presidente do Brasil, Luis Inácio Lula da Silva, em janeiro de 2002, compareceu como convidado especial na cerimônia oficial realizada em Brasília, em representação daquela forte organização sindical peninsular. Também em Brasília, no final do ano de 1999, recebeu o Título de Cidadão Honorífico da Cidade, outorgado pela Câmera Legislativa do Distrito Federal brasileiro. Naquela oportunidade, agradeceu com seu peculiar senso de humor, lembrando que a partir de então - com o título recebido - já não poderia ser expulso do país, referindo-se à tentativa de sua repatriação pelo governo conservador no ano de 1951, durante um percurso político nacional como presidente da União Internacional de Estudantes. A justificativa, nas suas próprias palavras, era que ele seria um "perigoso agente comunista russo disfarçado, cujo nome original seria Gofrei Berlik".

Por ocasião do seu falecimento, o presidente da República Italiana, Sergio Matarella, pronunciou em uma mensagem oficial as seguintes palavras com relação à "límpida figura de Giovanni Berlinguer".

Foi uma personalidade brilhante e dotada de um alto senso moral; médico de grande valor que soube unir na sua extensa trajetória, paixão civil e rigor científico, com um senso de profunda humanidade. 


\section{'Errando' pela América Latina}

Foram incontáveis as vezes em que Giovanni esteve na América Latina, convidado a participar em eventos científicos e congressos, além de proporcionar assessoria técnica e política a entidades e governos. Como tinha uma forma muito peculiar e bem-humorada de se expressar, em um de seus textos denominou a sua experiência na região como '20 anos errantes pela América Latina', dando à palavra 'errante' um duplo sentido: de 'erro', de estar aqui cometendo erros; e de 'errar' por se tratar de uma pessoa de vida livre que andava para cima e para baixo pela região, sem nenhum compromisso ou responsabilidade.

Pela sua atuação na Itália, seu nome, além de se tornar conhecido em diferentes partes do mundo, tornou-se especialmente referência na América Latina, onde parte de seus livros tiveram uma calorosa acolhida, sendo traduzida para o espanhol e para o português, a partir de final da década de 1970. Tais publicações, além de seu importante papel no desenvolvimento das políticas sanitárias em muitos países, foram diretamente responsáveis pela formação acadêmico-política de milhares de profissionais e militantes das mais diferentes profissões da saúde em toda a região.

Além da ação teórica acima mencionada, teve uma influência prática direta nos principais movimentos políticos do campo sanitário regional, através do seu apoio e participação ativa junto a combativos organismos como a Alames (Associação LatinoAmericana de Medicina Social) e o Cebes (Centro Brasileiro de Estudos de Saúde).

Países como Argentina, Brasil, Chile, Colômbia, Cuba, Equador, México, El Salvador, Uruguai e outros, cujo registro foge da nossa memória, receberam suas sempre simpáticas e profundas palavras em diferentes momentos, ainda durante os difíceis tempos em que ditaduras militares sangrentas assolaram a região. Assuntos diplomáticos como estes, complexos para um pesquisador estrangeiro, jamais o impediram de participar criticamente dos eventos e iniciativas aos quais era convidado. Pelo contrário, nessas ocasiões, o tom das suas intervenções se tornava ainda maior e mais crítico.

Em El Salvador, por exemplo, foi designado, no período inicial do pós-guerra, como um dos principais interlocutores internacionais para trabalhar na difícil construção dos acordos de paz que até hoje perduram entre os revolucionários de esquerda lutando pela igualdade e a democracia, e os governantes da direita autoritária que governava o país.

No Brasil, a difícil construção da reforma sanitária nacional, que culminou com a universalização constitucional do acesso de todas as pessoas à saúde e que foi o resultado de quase duas décadas de luta, teve em Berlinguer um dos seus mentores intelectuais e seu patrão.

No Brasil, participou de Conferências Nacionais de Saúde, sempre como convidado especial e um de seus principais palestrantes. Na X Conferência, realizada no mês de setembro de 1996, marcou sua presença festiva e honrosa na Assembleia do Cebes, convocada paralelamente à Conferência, ocasião em que, por acaso, um dos autores do presente texto passava a gestão da presidência da entidade (Volnei Garrafa - gestão 1994/96) para o outro (Paulo Amarante - gestão 1996/98).

Muitos outros exemplos poderiam aqui ser lembrados, em diferentes países e nos mais diversos momentos. De qualquer forma, apesar das ditaduras e dos governos repressivos que Berlinguer vivenciou enquanto esteve 'errante' pela América Latina, seus livros e textos passaram ano após ano de mão em mão, contribuindo substantivamente para a efetiva politização da saúde em toda a região. 


\section{Da medicina social e saúde pública à bioética}

A chegada de Berlinguer à bioética, além de constituir um marco importante para a área pela sua capacidade crítica de adicionar novas visões e interpretações, foi especialmente providencial no sentido da revisão dos seus fundamentos em relação aos macro temas cotidianos trabalhados até então de modo muito superficial pela teoria principalista dentro do seu estrito 'principio de justiça', de visão unilateral anglo-saxão.

Sua mente inquieta dividiu teoricamente a temática da bioética em dois grandes campos: a bioética das situações limites e de fronteira do conhecimento; e a bioética das situações cotidianas, dos problemas que acontecem diariamente na vida das pessoas, comunidades e nações. Dentro destas divisões, incorporou todo seu conhecimento de saúde pública e das situações com ela relacionadas. No cerne das situações limites estavam os assuntos produzidos pelo desenvolvimento científico e tecnológico; e no dos assuntos cotidianos, estavam a exclusão social, a não universalidade ao acesso à saúde, a inequidade na atenção sanitária, a pobreza, o analfabetismo etc.

Assim, as ideias de Berlinguer começaram a 'contaminar' a agenda bioética internacional com assuntos histórico-sociais, temas estes muito bem aproveitados pela bioética latinoamericana a partir do início do século XX, especialmente depois do sexto Congresso Mundial realizado em Brasília, quando aconteceu a primeira reunião efetiva com vistas à criação da Rede Latino-Americana y do Caribe de Bioética da Unesco - Redbioética. Se por um lado, não cabe dúvida com relação à paternidade da politização da agenda bioética internacional por parte da Redbioética, por outro, uma das sementes iniciais mais vigorosas deste forte processo dinâmico e dialético foi plantada por Berlinguer, com suas reflexões que construíram uma ponte inicial indispensável entre a (bio)ética e as questões sociopolíticas da atualidade.

Em termos mais concretos, suas ideias tiveram uma expressiva recepção na Unesco. Como membro de seu International Bioethics Committee, como dito anteriormente, foi designado no ano de 2003 relator do rascunho inicial que serviu de base para a futura Declaração Universal sobre Bioética e Direitos Humanos, que só seria homologada em 2005, depois de muitas e controversas versões iniciais. Suas ideias politicamente progressistas, que incluíam fortemente os assuntos sociais, ficaram plasmadas, sem dúvida, na mente dos demais membros que participavam do processo, de modo que acabaram fazendo parte do texto final, ainda que com algumas mudanças que acabaram acontecendo como consequência das incontáveis consultas e discussões.

Entre seus livros dedicados exclusivamente à ética e bioética, não se podem deixar de mencionar os seguintes: 'Questioni di vita - etica, scienza, salute' (BERLINGUER, 1991B); 'Etica, salud y medicina' (BERLINGUER, 1994); 'Etica della salute' (BERLINGUER, 1994); 'La merce finale saggio sulla compravendita di parti del corpo umano' (BERLINGUER; GARRAFA, 1996); 'II nostro corpo in vendita - cellule, organi, DNA e pezzi di ricambio' (BERLINGUER; GARRAFA, 2000); 'Bioetica quotidiana' (BERLINGUER, 2000).

\section{Considerações finais - o legado histórico de Giovanni Berlinguer}

As iniciativas legislativas de Berlinguer foram decisivas para a construção de normas nacionais que mudaram profundamente a sociedade italiana, como a Lei 833 que instituiu o Serviço Sanitário Nacional (BERLINGUER; SCARPA, 1974), a Lei 194 ligada à interrupção voluntária da gravidez (aborto) (BERLINGUER, 1978A, 1978C) e a Lei 180, com o apoio direto do também saudoso Franco Basaglia, 
que foi responsável pelo fim da instituição dos manicômios. Nos últimos anos, sua contribuição esteve focada no campo da bioética, para a qual ele foi um dos principais protagonistas internacionais, por meio de constantes participações em atividades institucionais e de produção de orientações teóricas decisivas aos avanços no sentido de um debate mais politizado e mais humano desta disciplina no mundo.

A preocupação constante com a interlocução, com o diálogo e a reflexão estão entre as principais virtudes de Berlinguer, um cientista sempre atento a expor dialeticamente argumentos tanto divergentes quanto concordantes com suas opiniões, procedentes de autores e tendências de orientações também diversas. Sua força criadora, aliada ao seu espírito persistente e indomável de militância, sempre funcionou ao lado de uma surpreendente simplicidade e humildade, um dos seus rasgos mais importantes e próprio dos 'grandes'.

Determinado em não deixar seus leitores com dúvidas, sempre procurou expressar o número de argumentos necessários para afastar qualquer sombra de incerteza.

Em seus textos científicos, especialmente nos livros, seu cuidado essencial foi de introduzir os temas através de rigorosos dados epidemiológicos da realidade com respeito ao assunto estudado para, em seguida, ir dissecando-os de forma crítica, um depois do outro, com uma racionalidade lógica avassaladora. Seus argumentos raramente deixavam arestas.

\section{Referências}

BERLINGUER, G. Minhas pulgas. São Paulo: Hucitec, 1991a.

Le salute nelle fabbriche. Bari: Ed. De Donato.

Bari, 1983.
Mesmo seus adversários mais persistentes reconheciam sua lógica horizontal e sua habilidade com as informações e ideias para tratar desde assuntos simples até os mais complexos.

É indispensável registrar que mais de uma dezena de livros de Giovanni foram traduzidos para o português e publicados no Brasil, a maioria deles em coleções dirigidas pelo Cebes, entidade da qual tinha admiração e um carinho muito especial e para a qual, segundo informou pessoalmente aos autores deste texto, doou integralmente todos os seus direitos autorais. Algumas destas obras estão disponíveis para os leitores interessados na biblioteca virtual do Cebes.

Aliás, em temas com os quais sua aflição humana era maior, tornava-se polemista de forma aguda e extremamente dura, utilizando referenciais epidemiológicos atualizados, mas não meramente numéricos, assépticos, frios e remotos à realidade, e sim dialeticamente fundamentados em uma epistemologia solidamente fundamentada. Assim, nestas oportunidades, sofria uma mudança radical, transmutando-se de cientista sóbrio a ator sociopolítico incisivo, que combatia a seus adversários com argumentos fortes e sólidos, utilizando grandes conceitos universais e uma enorme visão de futuro.

Com a morte de Giovanni Berlinguer o mundo se empobreceu; tornou-se menos crítico, menos orgânico, menos alegre, menos sábio e nós, seus seguidores e amigos, ficamos órfãos. 
Etica della salute. Milano: II Saggiatore, 1994.

Etica, salud y medicina. Montevideo: Editorial

Nordan-Comunidad, 1994

II dominio dell'uomo. Milano: Feltrinelli, 1978b.

La legge sul'aborto. Roma: Editori Riuniti, 1978c.

La macchina uomo. Roma: Editori Reuniti, 1960.

La malatia. Roma: Editori Riuniti. São Paulo:

Hucitec, 1984.

La sanità pubblica nella programazione econômica. Roma: Leonardo - Edizioni Scientifiche, 1964.

Malaria urbana: patologia delle metropoli. Milano: Feltrinelli, 1976a.

Medicina e política. Bari: Ed. De Donato, 1973.

Medicina e política. São Paulo: Hucitec, 1978d. (Coleção Saúde em Debate).

Psichiatria e potere. Roma: Editori Reuniti, 1969.

Psiquiatria e poder. Belo Horizonte:

Interlivros, 1976b.
Questioni di vita - etica, scienza, salute. Torino:

Giulio Einaudi Ed., 1991b.

Sicurezza e insecurezza sociale. Roma: Leonardo

- Edizione Scientifique, 1968.

BERLINGUER, G.; CECCHINI, I.; TERRANOVA,

F. Infortuni sul lavoro dei minori. Roma: II Pensiero

Scientifico, 1977.

BERLINGUER, G., GARRAFA, V. II nostro corpo in vendita: cellule, organi, DNA e pezzi di ricambio. Milano: Baldini \& Castoldi, 2000.

La merce finale - saggio sulla compravendita di parti del corpo umano. Milano: Baldini \& Castoldi, 1996.

BERLINGUER, G.; SCARPA, S. La riforma sanitaria. Roma: Editori Riuniti, 1974.

BERLINGUER, G.; TERRANOVA, F. La strage degli innocenti. Firenze: Nuova Italia, 1972. 